\title{
Profile and motivation for smoking cessation in surgical inpatients
}

\author{
Perfil e motivação para a cessação do tabagismo \\ em pacientes cirúrgicos hospitalizados \\ Perfil y motivación para dejar de fumar \\ en pacientes quirúrgicos hospitalizado
}

\begin{abstract}
Ana Paula Almeida Corrêa ${ }^{a}$ Isabel Cristina Echer ${ }^{b}$
\end{abstract}

DOl: $\quad$ http://dx.doi.org/10.1590/1983-

1447.2015.01.49133 a Master in Nursing, School of Nursing, Federal University of Rio Grande do Sul (UFRGS). Nurse, Clinical Hospital of Porto Alegre (HCPA) Porto Alegre, Rio Grande do Sul (RS), Brazil (BR).

${ }^{b}$ Doctor in Clinical Medicine, School of Medicine, UFRGS. Associate Professor, School of Nursing, UFRGS. Head of Surgical Nursing, HCPA. Porto Alegre, RS, BR.

\section{ABSTRACT}

The aim of this cross-sectional study was to describe the profile of smokers hospitalized for surgery, and investigate their motivation to quit. The sample consisted of 100 patients recruited from a university hospital in southern Brazil. Data were collected between February and May 2013, and analyzed using descriptive statistics. The sample was predominantly male $(n=58 ; 58 \%)$ and had a mean age of $54.5 \pm 13.8$ years. Seventy-nine (79\%) of the participants were white, 38(38\%) were married and 67(67\%) had primary education only. Patients started smoking at a mean age of $17 \pm 6.6$ years, smoked approximately 20(10 to 28.7) cigarettes/day and had been smoking for a mean of $37.4 \pm 14.4$ years. Ninety-one (91\%) patients wanted to stop smoking, $57(57 \%)$ were in the preparation phase, 36(36\%) had low nicotine dependence and 35(35\%) had been encouraged to quit. We concluded that, although hospitalization is a good moment to address smoking cessation, health care professionals do not enact effective and systematic interventions in this regard.

Keywords: Smoking cessation. Patient care team. Health facility environment.

\section{RESUMO}

Estudo transversal que objetivou identificar o perfil e a motivação para a cessação do tabagismo em pacientes cirúrgicos hospitalizados. A amostra foi aleatória, com 100 pacientes de um hospital universitário do Sul do Brasil. Os dados foram coletados entre fevereiro e maio de 2013 e analisados pela estatística descritiva. Os resultados evidenciaram que 58 (58\%) eram homens, com idade de 54,5 $\pm 13,8$ anos, $79(79 \%$ ) brancos, 38(38\%) casados e 67 (67\%) com ensino fundamental. 0 início do fumo ocorreu aos 17 $\pm 6,6$ anos, com consumo de 20(10-28,7) cigarros/dia e com 37,4 14,4 anos de fumo. Noventa e um (91\%) pacientes desejavam parar de fumar, 57(57\%) estavam na fase de preparação, 36(36\%) apresentavam baixa dependência de nicotina e 35(35\%) receberam incentivos para cessar o tabagismo. Conclui-se que a internação é um momento propício para abordagem do tabagismo, no entanto, a equipe de saúde ainda não intervém de maneira eficaz e sistematizada.

Palavras-chave: Abandono do hábito de fumar. Equipe de assistência ao paciente. Ambiente de instituições de saúde.

\section{RESUMEN}

Estudio transversal a identificar el perfil y la motivación para dejar de fumar en pacientes quirúrgicos. La muestra fue aleatoria con 100 pacientes de un hospital universitario en el sur de Brasil. Los datos fueron recolectados entre febrero y mayo de 2013 y analizados mediante estadística descriptiva. Los resultados mostraron que el 58(58\%) eran hombres, con edades de 54,5 $\pm 13,8$ años, 79 (79 \%)

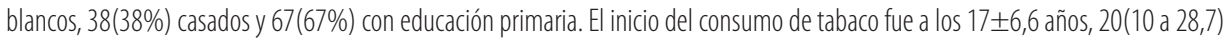
cigarrillos/día y 37,4 14,4 años fumadores. Noventa y un (91\%) pacientes querían dejar de fumar, 57(57\%) se encontraban en la fase de preparación, 36(36\%) tenían baja dependencia de la nicotina y 35(35\%) recibieron incentivos para dejar de fumar. Llegamos a la conclusión de que la hospitalización es un buen momento para la aproximación, sin embargo, el equipo de salud todavía no interviene con eficacia y de manera sistemática.

Palabras clave: Cese del tabaquismo. Grupo de atención al paciente. Ambiente de instituciones de salud. 


\section{DINTRODUCTION}

There are approximately one billion smokers in the world, of whom 800 million are men, and 200 million are women. Eighty percent of these men and $50 \%$ of these women live in underdeveloped or developing countries. These are disturbing figures given the association between tobacco use and a high rate of comorbidities such as cancer, diabetes, cardiovascular conditions and lung disease, which are responsible for $63 \%$ of all deaths worldwide. Six million people die annually from tobacco-related causes, and if the trend continues, tobacco will be responsible for eight million deaths in $2030^{(1)}$.

Tobacco control policies have made significant contributions to smoking cessation rates, since people are more likely to quit when more severe restrictions are imposed on smoking ${ }^{(2-3)}$. In hospital settings, patients are forced to stop smoking regardless of their motivation to quit, allowing them to stop and reflect on their life habits ${ }^{(4)}$. Additionally, hospitalized smokers are usually more receptive to anti-smoking messages given the fragility of their situation, their fear of death, and their acceptance of their disease and its severity ${ }^{(3)}$.

During hospitalization, it may be difficult to distinguish between symptoms of nicotine abstinence and the anxiety caused by the hospitalization itself. Therefore, hospitalized smokers require specialized treatment and additional support from the health care staff. However, even though hospitalization is known to be an opportune moment for smoking cessation, few institutional initiatives have been developed to treat hospitalized smokers ${ }^{(5)}$.

The most recommended treatment for smoking cessation is cognitive-behavioral therapy, which combines cognitive interventions and behavioral skills training, contributing to both cessation and relapse prevention. This is an effective method which focuses on the self-control required to escape the dependency, allowing the patient to become the protagonist of his own behavior change. These findings underscore the need for health professionals to implement a basic intervention to encourage cessation in smoking inpatients ${ }^{(3)}$.

Knowledge regarding the profile of smokers hospitalized in surgical units and their motivation to stop smoking may play a crucial role in the development of effective strategies to encourage these individuals to quit. As such, the goal of this study was to describe the profile and cessation motivation of smokers hospitalized for surgery.

\section{口 METHOD}

This cross-sectional study was performed as part of a master's dissertation(6), and involved smokers who were hospitalized in the surgical units of a large university hospital in southern Brazil between February and March 2013.

The sample size required to estimate the prevalence of smoking among inpatients was calculated based on studies performed in other hospitals, in which the prevalence of smoking was found to be $20 \%(4,7)$. As such, the minimum sample size for the present study was calculated at 77 smokers.

Inclusion criteria consisted of age 18 years or older, and admission to the inpatient surgery units of the hospital. Patients with neurological, psychiatric or clinical conditions which prevented them from comprehending or responding to the interview, who were absent from their hospital beds on both data collection visits, who were discharged within less than 72 hours and who were readmitted during the study period were excluded from the sample.

Data were collected with the help of research assistants, all of whom signed a special informed consent form. All assistants were adequately trained and provided with a manual containing information regarding data collection procedures.

The first step in data collection involved the printing of a list of admissions to the surgical units of the hospital. The list was checked daily and new patients were recruited until the required sample size was achieved. The smoking status of each patient was obtained from electronic medical records, or asked directly to the patient when electronic information was not available. Inpatients classified as smokers were then approached and informed as to the goals of the study, and the importance of their participation. Those who agreed to take part in the study were then interviewed for data collection. At a third point in time, patients' reasons for admission and clinical data were obtained from electronic hospital records.

Smoking status was classified as follows: smoker (smokes one or more cigarettes a day on a regular basis, or abstinent for less than 6 months), abstinent smoker (used to smoke but has not done so for at least six months) and nonsmoker (never smoked, or experimented with smoking without becoming a smoker).

The data collection instrument contained questions regarding sociodemographic, economic and clinical parameters, as well as smoking history, symptoms caused by smoking and nicotine abstinence, treatments and information concerning smoking cessation received during hospitalization, and patient motivation to quit. 
Table 1. Sample characteristics and smoking history. Porto Alegre, RS, Brazil, 2013.

Age (years) *

Sex (male)

Race (white)

Marital status

Married/in relationship

Separated/Divorced/Widowed

Single

\section{Education level}

Primary

Secondary

University

Place of birth

Rio Grande do Sul - Countryside

Porto Alegre metropolitan area

Out of state

\section{Personal income}

Family income

Number of family members ${ }^{\dagger}$

Age of smoking onset*

Years of smoking*

Cigarettes per day ${ }^{\dagger}$

Days since last cigarette

Wants to quit smoking (yes)

Motivation to quit smoking (0 to 10 ) *

Has tried to quit (yes)

Number of attempts at quitting ${ }^{\dagger}$

Sought help to stop smoking (yes)

Sought treatment to stop smoking (yes)

Spends time with smokers(yes)
$67(67)$

$20(20)$

$54.5(13.8)$

$58(58)$

$79(79)$

38 (38)

34 (34)

28 (28)

$13(13)$

57 (57)

37 (37)

6 (6)

$800(700-1800)^{\ddagger}$

$1400(700-2850)^{\ddagger}$

$2(2-4)$

$17(6.6)$

$37.4(14.4)$

20 (10-28.7)

6 (4-12.75)

91 (91)

$8.4(2.4)$

77 (77)

$1(1-2)$

$12(12)$

$11(11)$

$68(68)$

Source: Research data, 2013

Categorical data presented as $n(\%)$

Continuous variables assessed using the Shapiro-Wilk test *variables expressed as mean and standard deviation, variables expressed as median and interquartile range (25-75), ‡values expressed in R\$̧ (Brazilian real)

The Fagerström ${ }^{(8-9)}$ and Prochaska and Di Clemente scales were also used for data collection. Both of these instruments have been validated for use in Brazil(10). The Fagerström Scale contains six questions whose scores are summed to produce a total ranging from zero to ten, which can be used to classify nicotine dependence as very low (scores $0-2$ ), low (scores 3-4), moderate (5), high (scores 6-7) and very high (scores 8-10). The Prochaska and Di Clemente scale assesses motivation to quit based on the cognitive and motivational stages involved in the quitting process: precontemplation (does not consider quitting in the next six months), contemplation (is motivated to quit in the next six months), action (has stopped smoking, and has been abstinent for $<6$ months), maintenance (has not 


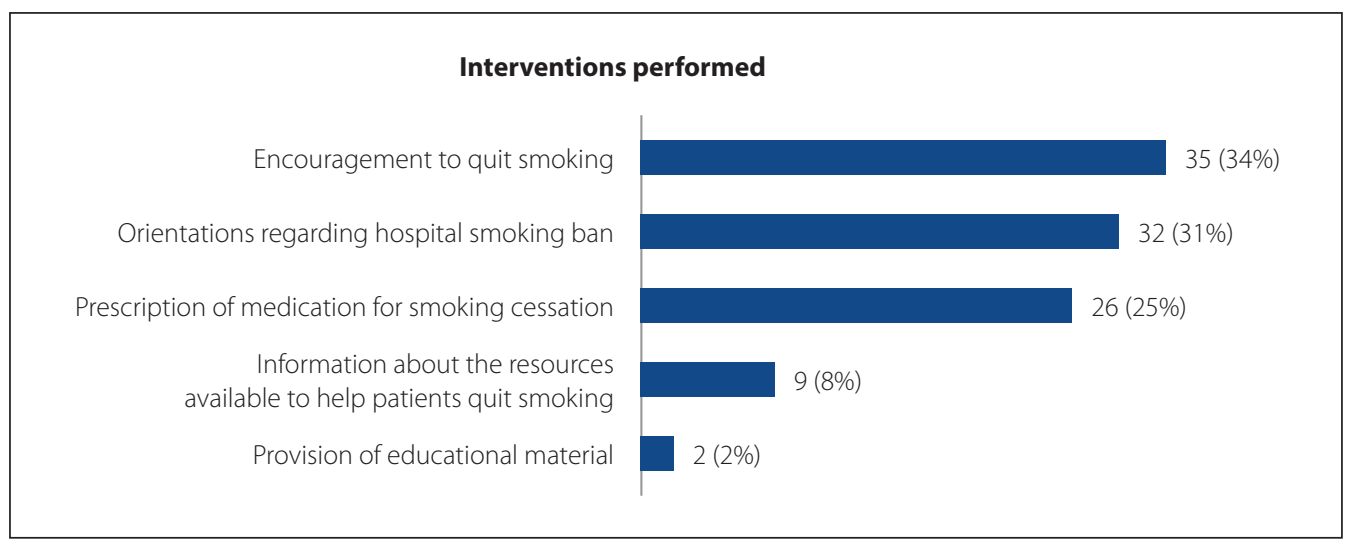

Graph 1. Interventions and guidance offered by health care workers to encourage smoking cessation in hospital inpatients. Porto Alegre, RS, Brazil, 2013.

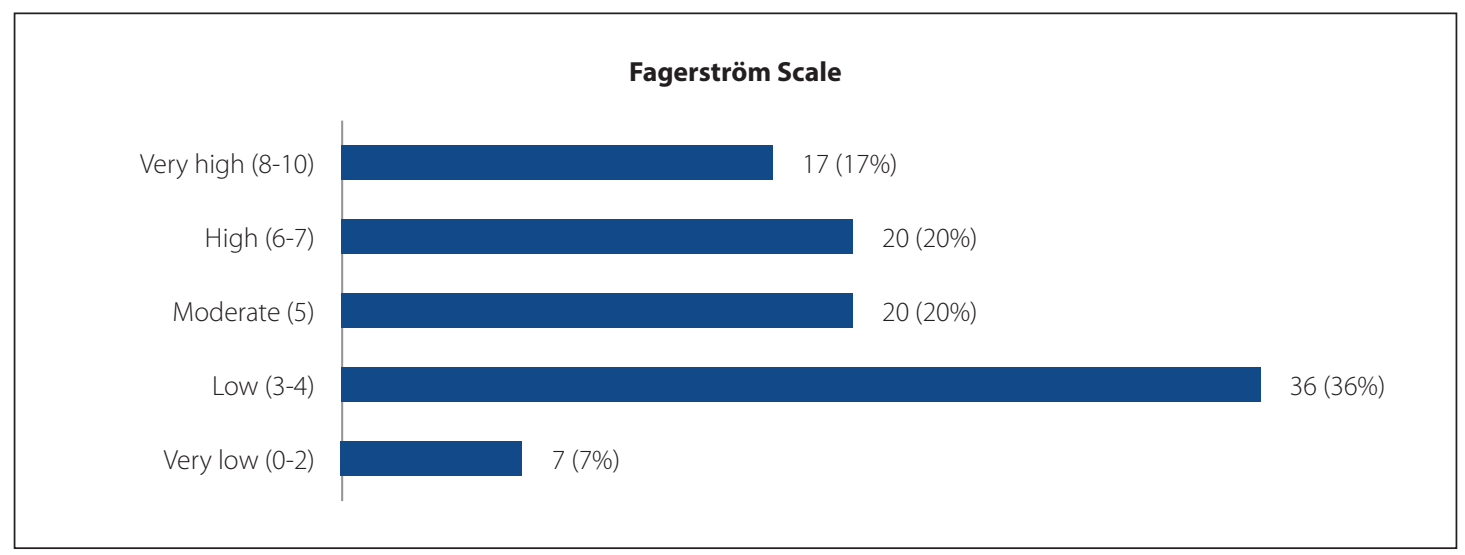

Graph 2. Fagerström Scale. Porto Alegre, RS, Brazil, 2013.

smoked for six months or longer) and relapse (managed to quit before relapsing and returning to smoking).

Data were analyzed using the Statistical Package for Social Sciences (SPSS), version 18.0, which was used to calculate absolute and relative frequencies, as well as measures of central tendency, dispersion and position. Data normality was verified using the Shapiro-Wilk test. Continuous variables were described as mean and standard deviation or median and interquartile range. Categorical variables were summarized by absolute and relative frequencies.

The present study was performed according to Brazilian Guidelines and Regulations for Human Research (11), and was approved in 2012 by the Research Ethics Committee of the Clinical Hospital of Porto Alegre (CEP/HCPA), under project number 12-0461. Upon enrolment, patients signed an informed consent form which guaranteed their anonymity, ensured that their data would be used exclusively for research purposes, and gave them the right to with- draw from the study at any time. The authors also signed a consent form for institutional data use prior to accessing electronic medical records.

\section{RESULTS}

Of the 1439 patients whose records were evaluated and classified according to smoking status, 938 (65\%) nonsmokers, 281 (20\%) were abstinent smokers and 210(15\%) were smokers. Fifty-nine of the latter were discharged less than 72 hours following admission or were not in their hospital beds on either data collection visit, 12 did not agree to participate in the study, 29 were not in physical condition to answer the questionnaire and 10 were quarantined. As such, 100 patients were included in the present study. Table 1 shows the profile of inpatient smokers in terms of their demographic and economic characteristics, as well as their smoking history. 


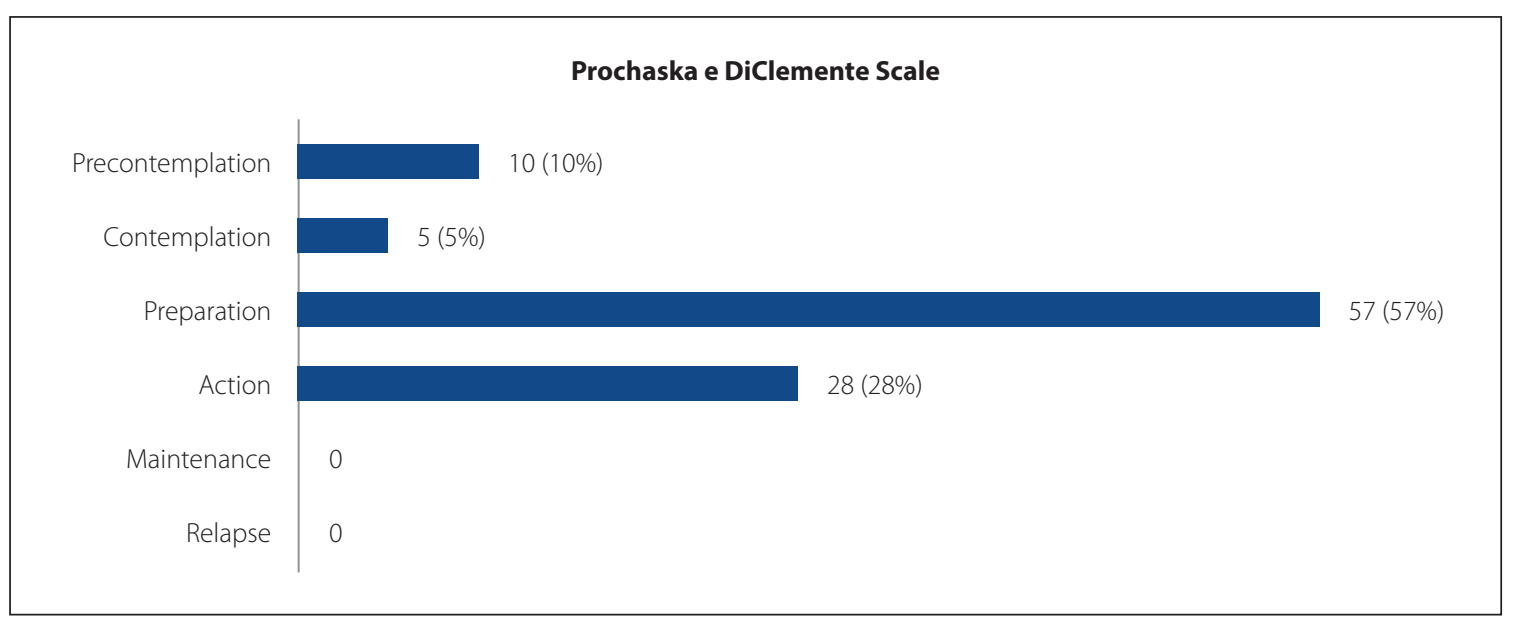

Graph 3. Prochaska and DiClemente scale. Porto Alegre, RS, Brazil, 2013.

Twelve (12\%) of the participants sought doctors and support groups to quit smoking, while 11 (11\%) used nicotine patches, chewing gum, inhalers or medication. Sixty-eight (68\%) patients regularly interacted with other smokers, most of whom were family and close friends.

Patients were recruited from several units in the hospital, including gastroenterology/proctology/general surgery $(n=36 ; 36 \%)$, urology/nephrology $(n=23 ; 23 \%)$, cardiology $(n=13 ; 13 \%)$, traumatology/orthopedics $(n=11 ; 11 \%)$, and other units such as gynecology, neurosurgery, pneumology, and ophthalmology ( $n=17 ; 17 \%)$.

Of the 94 patients (94\%) who reported smoking-related symptoms, 66 (66\%) presented with coughing and/ or sputum production, 50(50\%) with wheezing and/or shortness of breath, 37(37\%) with chest pain and/or palpitations, 79(79\%) with fatigue, cramps and/or leg pain, and $35(36 \%)$ with dizziness and/or fainting. Eighty-one (81\%) patients reported nicotine abstinence symptoms during hospitalization, such as insomnia ( $n=46 ; 45 \%)$, irritability $(n=25 ; 25 \%)$, anxiety $(n=48 ; 48 \%)$, depression $(n=29 ; 29 \%)$ and changes in appetite $(n=52 ; 52 \%)$

Graph 1 illustrates the interventions and guidance offered by health professionals to help patients quit smoking. Each patient may have been approached more than once by different members of the staff.

Of the 35 (34\%) health care workers who offered support/treatment to smokers, 22(63\%) were doctors, seven (20\%) were nurses, one (3\%) was a nurse technician and five (14\%) were other health care staff.

When patients were asked as to their reasons to quit smoking, 83(71\%) cited health concerns, 16(14\%) were worried about their families, 14(12\%) mentioned aesthetic and/or financial reasons, and four (3\%) did not mention any specific reasons (each patient could give more than one reason in response to this question). When asked as to reasons to continue smoking, 60(60\%) patients gave no reason at all, 14(14\%) cited emotional issues, and eight (8\%) mentioned nicotine dependence. Nineteen (19\%) participants identified other reasons, such as the taste and pleasure associated with smoking, the habit of smoking itself, socialization, distraction and the fear of being unable to quit.

Graphs 2 and 3 show the degree of nicotine dependence in the sample according to the Fagerström Scale ${ }^{(7-8)}$, and patient motivation to quit as per the Prochaska and DiClemente ${ }^{(10)}$ scale.

\section{DISCUSSION}

The prevalence of smoking identified in the present study (15\%) was similar to that reported by investigations performed in other general hospitals in the country ${ }^{(4-5,7,12)}$. The high number of participants who actively smoked at the time of admission may be attributable to the fact that most subjects in our sample of surgical patients had been admitted for elective procedures. These findings underscore the importance of evaluating and understanding patients' smoking habits before hospital admission to provide adequate support and interventions to help them quit smoking prior to undergoing surgery.

The sociodemographic and economic characteristics of the sample were similar to those described in other similar studies ${ }^{(4,5,7,11-15)}$. Patients were, on average, 54 years old, and had therefore reached an age at which the comorbidities associated with lifestyle factors often begin to appear. 
Since smoking poses a significant health risk, and most patients had been smoking for long periods of time, we believe that this may have contributed to the hospitalization of patients in the present study.

Studies show that smoking is more prevalent in men, especially in developing countries ${ }^{(1)}$. Smoking has also been found to be associated with features of social inequality such as low income and low education levels, which underscores the need for tobacco control programs and policies in populations with low socioeconomic status ${ }^{(16)}$.

Most participants in the present study started smoking in adolescence. According to the literature, individuals in this age group associate smoking with freedom and independence ${ }^{(5,12-13,17)}$. As such, it is important to address the issue of smoking in both child and adolescent populations, to prevent young people from taking up the habit and becoming smokers in adulthood.

According to the literature, smokers consume an average of 20 cigarettes per day. This figure is similar to that observed in the present study, but paints a disturbing picture since the severity of tobacco-related diseases tends to increase with the number of cigarettes smoked per day and the number of years spent smoking ${ }^{(4-5)}$. The number of cigarettes smoked per day tends to increase over the years, which makes quitting even more difficult and causes progressively greater impact on health.

Most smokers in the present sample had made previous attempts to quit, as is often found in similar studies in the literature ${ }^{(12,14-15)}$. Nicotine is an addictive substance, which further complicates the process of quitting, so that although many people may wish to stop smoking, few succeed without assistance. This is illustrated by the fact that only a small percentage of the sample had sought help or treatment to quit smoking.

Sources of assistance included doctors and support groups, as well as treatments such as nicotine patches, chewing gum, inhalers and medication. The combination of pharmacological treatment and behavioral interventions has been found to be an effective method of achieving cessation ${ }^{(18-19)}$. During hospitalization, smokers are more likely to begin the quitting progress, since they are abstinent and in daily contact with health care workers who may support his efforts.

Almost $70 \%$ of patients in the present sample have daily interactions with smokers, who are usually close friends or family members. The association between the difficulty of quitting and proximity to other smokers has been evidenced by several studies $(5,13,17)$. This finding reinforces the need to involve family and friends in cessa- tion interventions as a way to encourage the smoker to remain abstinent.

The patients in the present study had been hospitalized for widely varying reasons, as tends to be the case in similar studies performed in large hospitals ${ }^{(4,7)}$. Patients who smoke need encouragement and guidance from the health care team to ensure they are successful in quitting regardless of their underlying illness or reason for hospital admission. As such, health professionals of all disciplines must be trained to identify inpatient smokers and ensure they receive adequate treatment for smoking cessation.

The tobacco-related symptoms reported by participants in the present sample were similar to those identified in other studies ${ }^{(4-5,7)}$. Symptoms such as coughing, dyspnea, and palpitations may interfere with daily functioning and compromise health and quality of life. However, since some of the symptoms reported by patients may be caused by other underlying diseases rather than tobacco use, a thorough medical examination is always required in these cases.

According to the literature, patients who stop smoking shortly before hospital admission may experience nico-

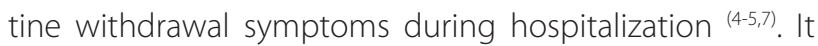
is therefore especially important that health care workers identify these symptoms during clinical assessment and implement interventions to assist patients with abstinence and relieve craving through medication use, nicotine patches and emotional support.

Few of the patients in the present sample received guidance or orientations from health care workers regarding smoking cessation. These are disappointing figures, especially when compared to those reported by studies performed in the United States, where this type of intervention is much more common ${ }^{(20)}$. These results show that there is still much work to be done to ensure these interventions are incorporated into the clinical routine of health care institutions in Brazil.

Patients in the present sample were more motivated to quit smoking than those evaluated in another similar study performed in the same hospital(17). During hospitalization, smokers often realize the severity of their health problems, which may trigger their desire to quit. As such, this is an ideal moment for the implementation of cessation interventions. Unfortunately, the present results showed that this is still not a regular practice in hospital settings, and that inpatients who smoke are not systematically approached and encouraged to quit.

Patients' main reasons for quitting included concerns about their health and their families, as has been ob- 
served in other similar studies ${ }^{(17)}$. These results show that subjects are aware of the health risks posed by smoking. However, nicotine dependence places a burden on the quitting process. As such, to ensure the success of cessation efforts, individuals must receive support and be given the opportunity to share their expectations and concerns with family and health care workers. Most participants did not give any reasons to continue smoking, although some identified the pleasure associated with smoking, the difficulty stopping the habit and the nicotine dependence itself as major obstacles to quitting. These findings agree with those reported by other studies in the literature ${ }^{(4,17)}$. Individuals who do not consider themselves nicotine-dependent believe they can quit smoking at any time; however, their attempts to do so without help are not usually successful and lead to relapse, which causes frustration.

Most participants in the present sample were classified as having low, high or very high nicotine dependence. Studies performed in similar samples have identified low to very high levels of nicotine dependence in different patient profiles ${ }^{(12,14,17)}$. The scale used in the present study is easily administered and can be used by health care workers to plan tobacco control interventions or to evaluate nicotine dependence in inpatient settings.

The Prochaska and Di Clemente scale revealed that most patients in the sample were in the preparation phase of the quitting process, which suggests they were considering quitting in the near future. This stage is followed by the action phase, in which subjects will already have stopped smoking. Hospitalization often leads smokers to reflect on the possibility of quitting(4). Since smoking is not allowed in hospitals, patients end up experiencing life without cigarettes. This has a beneficial effect for some patients, who begin to believe in their ability to resist nicotine and quit smoking.

\section{CONCLUSIONS}

The present results showed that inpatients who smoke are motivated and willing to quit, since hospital smoking bans, their own ill health, and the hospitalization itself may lead them to rethink their smoking status. As such, hospitalization may provide a suitable window for health care workers to implement cessation interventions to encourage patients to quit smoking.

Given the intensity of the contact and the close bond established between inpatients and the nursing staff, these professionals must play a more active role in encouraging smoking cessation. Health care teams, es- pecially nurses, must therefore be trained to approach smokers in a systematic manner, so that hospitalization can become an opportunity for behavioral change and health education.

The way in which tobacco use and nicotine abstinence symptoms were evaluated in the present investigation may have limited our findings, since it may not have been sufficiently accurate in discriminating between smoking-related symptoms and the consequences of patients' underlying diseases. Future studies may wish to analyze these variables more thoroughly by evaluating cases on an individual basis so as to avoid interpretation bias. We suggest that studies with stricter designs be performed on these populations to investigate any additional clinical issues which may have remained unexplored in the present study.

Despite these limitations, this study contributed significantly to the literature on the prevalence and profile of smokers in surgical inpatient units, and may serve as a basis for the development of more effective strategies to encourage inpatients to quit smoking.

\section{口EFERENCES}

1. World Health Organization (CH). WHO report on the global tobacco epidemic, 2011: warning about the dangers of tobacco. Geneva; 2011.

2. Echer IC, Luz AMH, Lucena AF, Motta GC, Goldim JR, Menna Barreto SS. A contribuição de restriç̄ôes sociais ao fumo para o abandono do tabagismo. Rev Gaúcha Enferm. 2008:29(4):520-7.

3. Reichert J, Araújo AJ, Gonçalves CMC, Godoy I, Chatkin JM, Sales MPU, et al. Diretrizes para cessação do tabagismo 2008. J Bras Pneumol. 2008;34(10):84580.

4. Barreto RB, Pincelli MP, Steinwandter R, Silva AP, Manes J, Steidle LJM. Tabagismo entre pacientes internados em um hospital universitário no sul do Brasil: prevalência, grau de dependência e estágio motivacional. J Bras Pneumol. 2012;38(1):72-80.

5. Ferreira AS, Campos ACF, Santos IPA, Beserra MR, Silva EN, Fonseca VAS. Tabagismo em pacientes internados em um hospital universitário. J Bras Pneumol. 2011;37(4):488-94.

6. Corrêa APA. Prevalência e perfil tabágico de pacientes adultos internados em unidades cirúrgicas de um hospital universitário [dissertação]. Porto Alegre (RS): Escola de Enfermagem, Universidade Federal do Rio Grande do Sul; 2014.

7. Oliveira MVC, Oliveira TR, Pereira CAC, Bonfim AV, Leitão FFS, Voss LR. Tabagismo em pacientes internados em um hospital geral. J Bras Pneumol. 2008;34(11):936-41.

8. Heatherton TF, Kozlowski LT, Frecker RC, Fagerström KO. The Fargerström test for nicotine dependence: a revision of the Fagerström tolerance questionnaire. $\mathrm{Br} J$ Addict. 1991;86(9):1119-27.

9. Carmo JT, Pueyo AA. A adaptação ao português do Fagerström test for nicotine dependence (FTND) para avaliar a dependência e tolerância à nicotina em fumantes brasileiros. Rev Bras Med. 2002;59(1/2):73-80. 
10. Yoshida EMP, Primi R, Pace R. Validade da escala de estágios de mudança. Estud Psicol. (Campinas). 2003;20(3):7-21.

11. Conselho Nacional de Saúde (BR). Resolução 466 de 2012. Diretrizes e normas regulamentadoras de pesquisa envolvendo seres humanos [Internet]. Brasília; 2012. [citado 2014 jan 6]. Disponível em: http://conselho.saude.gov.br/resolucoes/2012/Res0466.pdf

12. Silva RLF, Carmes ER, Schwartz AF, Blaszkowski DS, Cirino RHD, Ducci RD. Cessação de tabagismo em pacientes de um hospital universitário em Curitiba. J Bras Pneumol. 2011;37(4):480-7.

13. Russo AC, Azevedo RCS. Fatores motivacionais que contribuem para a busca de tratamento ambulatorial para a cessação do tabagismo em um hospital geral universitário. J Bras Pneumol. 2010;36(5):603-11.

14. Azevedo RCS, Higa CMH, Assumpção ISMA, Frazatto CRG, Fernandes RF, Goulart W, et al . Grupo terapêutico para tabagistas: resultados após seguimento de dois anos. Rev Assoc Med Bras. 2009;55(5):593-6.
15. Chaves EC, Oyama SMR. Aconselhamento telefônico para cessação do tabagismo. Rev Gaúcha Enferm. 2008;29(4):513-9.

16. Mahoney MC, Erwin D0, Widman C, Masucci Twarozek A, Saad-Harfouche FG, Underwood W, et al. Formative evaluation of a practice-based smoking cessation program for diverse populations. Health Educ Behav. 2014 Apr;41(2):186-96.

17. Echer IC, Corrêa APA, Lucena AF, Ferreira SAL, Knorst MM. Prevalência do tabagismo em funcionários de um hospital universitário. Rev Latino-Am Enfermagem. 2011;19(1):179-86.

18. Aizawa M, Kuroyama M, Przegl L. The pharmacist's role in smoking cessation. Nihon Rinsho. 2013;71(3):515-9.

19. Zieleń I, Sliwińska-Mossoń M, Milnerowicz H. Drugs used to treat nicotine addiction. Przegl Lek. 2012;69(10):1098-102.

20. Rei BA, Dube SR, Babb SDM, Timothy A. Patient-reported recall of smoking cessation interventions from a health professional. Prev Med. 2013;57(5):715-7.

\section{Author's address:}

Ana Paula Almeida Corrêa

Rua General Lima e Silva, 445/902, Cidade Baixa

90050-101, Porto Alegre, RS

E-mail: anacorrea.enf@gmail.com
Received: 25.07.2014

Approved: 12.02 .2015 